\title{
Growth of cyprinid herpesvirus 2 (CyHV-2) in cell culture and experimental infection of goldfish Carassius auratus
}

\author{
Takafumi Ito ${ }^{1, *}$, Jun Kurita ${ }^{2,6}$, Akiyuki Ozaki ${ }^{3}$, Motohiko Sano ${ }^{4,7}$, Hideo Fukuda ${ }^{5}$, \\ Mitsuru Ototake ${ }^{4,8}$
}

\author{
${ }^{1}$ Tamaki Laboratory, Aquatic Animal Health Division, 224-1 Hiruta, Tamaki, Mie 519-0423, Japan \\ ${ }^{2}$ Diagnosis and Training Center for Fish Diseases, ${ }^{3}$ Aquaculture Technology Division, ${ }^{4}$ Aquatic Animal Health Division, \\ National Research Institute of Aquaculture, Fisheries Research Agency, 422-1 Nakatsuhamaura, Minami-Ise, Mie 516-0193, Japan \\ ${ }^{5}$ Faculty of Marine Science, Tokyo University of Marine Science and Technology, 4-5-7 Konan, Minato, Tokyo 108-8477, Japan \\ ${ }^{6}$ Present address: Headquarters, Fisheries Research Agency, 15F Queen's Tower B, 2-3-3 Minato Mirai, Nishi, Yokohama, \\ Kanagawa 220-6115, Japan \\ ${ }^{7}$ Present address: Faculty of Marine Science, Tokyo University of Marine Science and Technology, 4-5-7 Konan, Minato, \\ Tokyo 108-8477, Japan \\ ${ }^{8}$ Present address: Research Center for Aquatic Genomics, National Research Institute of Fisheries Science, \\ Fisheries Research Agency, 2-12-4 Fukuura, Kanazawa, Yokohama, Kanagawa 236-8648, Japan
}

\begin{abstract}
Herpesviral haematopoietic necrosis has caused great economic damage to goldfish Carassius auratus aquaculture in Japan. The existence of cyprinid herpesvirus 2 (CyHV-2), the causative agent, has also been reported from several other countries. To prevent spread to other areas, basic virological information such as viral kinetics in infected fish is essential. Experimental infection trials using reliably prepared CyHV-2 for defining viral kinetics are difficult to carry out because successful and sustainable propagation of this virus in cell culture has previously been limited. Here we describe a method for sustainable propagation of CyHV-2 in cell culture, and the results of fish infection experiments using the propagated virus. We found that goldfish fin (GFF) cells and standard Ryukin Takafumi (SRTF) cells established from goldfish fin can be used for continuous propagation of CyHV-2. Experimental infections using 2 varieties of goldfish, Ryukin and Edonishiki, were performed with the virus passaged 7 times in GFF cells. In transmission experiments with water temperature at $20^{\circ} \mathrm{C}$, cumulative mortality was $30 \%$ in Ryukin infected by immersion, and 90 and $100 \%$ in Edonishiki and Ryukin intraperitoneally injected with the virus, respectively. In an experiment carried out at $25^{\circ} \mathrm{C}, 90 \%$ of Edonishiki challenged by immersion died. PCR detection of viral DNA from the organs of infected fish showed that systemic infection occurs and also that the kidney is a main viral multiplication site. Moreover, CyHV-2 was successfully re-isolated in GFF cells from the dead fish.
\end{abstract}

KEY WORDS: Herpesviral haematopoietic necrosis · Cyprinid herpesvirus $2 \cdot$ Goldfish fin (GFF) cells $\cdot$ Experimental infection $\cdot$ Viral kinetics

\section{INTRODUCTION}

Herpesviral haematopoietic necrosis (HVHN) has caused great economic damage to goldfish Carassius auratus aquaculture in Japan since it was initially reported in 1992 (Jung \& Miyazaki 1995, Aichi Prefec- ture 2008). The disease is now recognized as a major pathogen of goldfish not only in Japan but also in the USA (Groff et al. 1998, Goodwin et al. 2006a), Taiwan (Chang et al. 1999), Australia (Stephens et al. 2004), New Zealand (Hine et al. 2006) and the UK (Jeffery et al. 2007). The causative virus of the disease 
was named goldfish haematopoietic necrosis virus (GFHNV) in the first report (Jung \& Miyazaki 1995), and as this virus is the second herpesvirus isolated from a cyprinid species, it was formally designated as the species Cyprinid herpesvirus 2 (CyHV-2) following the rules for nomenclature of the International Committee on the Taxonomy of Viruses. Although it was thought that this virus shows virulence only to goldfish, Wang et al. (2012) reported that mass mortality caused by CyHV-2 infection occurred in Prussian carp Carassius gibelio in China. Furthermore, Daněk et al. (2012) detected this virus from the same species in the Czech Republic. These reports suggest that this virus has been spreading by movement of diseased or carrier fish and also that CyHV-2 has the potential to infect other species of the genus Carassius.

To prevent further spread of this disease to other areas and to potential new hosts, information relating to viral kinetics in fish, epidemiology and development of control measures is clearly essential. However, studies based on experimental infection trials using cultured virus, as a reliable infectious inoculum, are difficult to carry out, because isolation from diseased fish and subsequent continuous propagation of this virus in cell culture has been limited (Jung \& Miyazaki 1995, Li \& Fukuda 2003). Jung \& Miyazaki (1995) reported isolation of CyHV-2 using fathead minnow (FHM) cells. However, CyHV-2 could not be propagated beyond the fourth passage. Jeffery et al. (2007) and Wang et al. (2012) also reported isolating CyHV-2 using koi fin (KF-1) cells, but the isolated virus was not continuously propagated in either study. In another case, Li \& Fukuda (2003) succeeded in the propagation of the virus using goldfish fin (GFF) cells, and Waltzek et al. (2005, 2009a,b) also reported propagation of the virus using goldfish fin (GF-1) cells. It should be noted that GFF and GF-1 are the same cell line originally distributed by $\mathrm{H}$. Fukuda. To date, the study by Jung \& Miyazaki (1995) is the only report of experimental infection via intraperitoneal injection with cultured virus. To date, no report has documented experimental infection by viral immersion.

Here we describe a method for sustainable propagation of CyHV-2 using the GFF cell line (Li \& Fukuda 2003) and a newly established cell line also from goldfish fin (standard Ryukin Takafumi, SRTF). Experimental infections of 2 varieties of goldfish (Ryukin and Edonishiki) were performed using virus that had been passed 7 times in cell culture as an inoculum, at 2 water temperatures $\left(20\right.$ and $25^{\circ} \mathrm{C}$ ). In addition, the organs of Edonishiki experimentally infected by immersion were tested to investigate the prevalence of viral DNA at selected intervals following viral exposure.

\section{MATERIALS AND METHODS}

\section{Cell line}

Three cell lines, GFF (Li \& Fukuda 2003), SRTF and Ryukin fin (RKF) from the fin of Ryukin goldfish, were prepared for this study. The GFF cell line was established at the Tokyo University of Marine Science and Technology, and the SRTF and RKF cell lines were established in the Tamaki laboratory of the National Research Institute of Aquaculture (NRIA).

Cultures of these cell lines were maintained in minimum essential medium (MEM; Mediatech) supplemented with $10 \%$ foetal bovine serum (FBS; Equitech-Bio) and antibiotics (100 U penicillin $\mathrm{ml}^{-1}$ and $100 \mathrm{mg}$ streptomycin $\mathrm{ml}^{-1}$ ). For successful attachment and growth, SRTF cells required the flasks to be coated with collagen type I (e.g. IWAKI code no. 4100-010). All cell lines were maintained at $25^{\circ} \mathrm{C}$. Sub-culture of these cell lines was carried out once every 2 to $3 \mathrm{wk}$ at a split ratio of 1:2 or 1:3.

\section{Virus}

The virus used for the present study was the CyHV-2 Saitama-1 (SaT-1) isolate which was isolated in GFF cells from diseased calico goldfish in Saitama Prefecture, Japan, in 1999. The original virus was passed once through goldfish at $24.1^{\circ} \mathrm{C}$ by intraperitoneal injection into 6 individuals of Wakin goldfish (average body weight $12.2 \mathrm{~g}$ ) obtained from a retailer. After the injection, 1 fish died on Day 7 and another on Day 12. The homogenate of pooled kidney from both dead fish was inoculated onto monolayers of $\mathrm{GFF}$ cells at $20^{\circ} \mathrm{C}$ for re-isolation of the virus. CyHV-2 SaT-1 isolate recovered from these cultures was used for further studies.

\section{Method for continuous propagation of the virus in cell culture}

To examine the passage of CyHV-2 in GFF cells, SRTF cells and RKF cells, an aliquot $(500 \mu \mathrm{l})$ of the viral stock after centrifugation $\left(400 \times g, 10 \mathrm{~min}, 4^{\circ} \mathrm{C}\right)$ was inoculated into newly sub-cultured cell suspensions in $25 \mathrm{~cm}^{2}$ flasks, and then these flasks were incubated at $25^{\circ} \mathrm{C}$. If, after $7 \mathrm{~d}$ incubation, the cytopathic effect (CPE) had not progressed to affect at least $30 \%$ of the monolayer, then infected cells were sub-cultured after addition of new medium to the existing medium in the flask, at a split ratio of $1: 2$ or 
1:3. The virus was sub-cultured by these methods 7 times, after which aliquots of the cell culture supernatant containing CyHV-2 were placed in $3.6 \mathrm{ml}$ cryo tubes (Nunc ${ }^{\circledR}$, Thermo Fisher Scientific) and stored at $-85^{\circ} \mathrm{C}$ until use. One aliquot was thawed, and each of the 8-well columns of 96-well microplates, seeded with newly sub-cultured GFF cell suspensions, was inoculated with serial 10-fold dilutions of virus stock and incubated at $25^{\circ} \mathrm{C}$ to obtain the $\mathrm{TCID}_{50}$ titre of the viral stock used in subsequent experiments.

\section{Fish}

Two varieties of goldfish, Ryukin and Edonishiki, were used for experimental infections. Ryukin and Edonishiki were bred from CyHV-2-free broodstock at the Tamaki laboratory, NRIA. Eggs of both strains were disinfected with iodophor (200 $\mathrm{mg} \mathrm{l}^{-1}, 15 \mathrm{~min}$ ) immediately after fertilization. Fry of both varieties of goldfish were fed water fleas (Daphnia sp.) until 14 to $21 \mathrm{~d}$ after hatching and were fed commercial pellets (Saki-Hikari ${ }^{\circledR}$, Kyorin) afterwards. All stages were maintained in well water to prevent, as far as possible, any infection from pathogens.

\section{Detection of viral DNA from fish by PCR}

For the specific detection of CyHV-2, the PCR (polymerase chain reaction) described by Waltzek et al. (2009b) was employed. The DNA template for positive control was extracted from the supernatant of virus-infected cell cultures using InstraGene ${ }^{\mathrm{TM}}$ Matrix (Bio-Rad Laboratories). For samples of each organ of the experimentally infected fish, total DNA was extracted from tissues using the Gentra Puregene Tissue Kit (Qiagen). The PCR reaction mixture used was TaKaRa Ex Taq ${ }^{\circledR}$ Hot Start Version (TaKaRa) according to the manufacturer's protocol. The thermocycling profile was performed according to published protocols (Waltzek et al. 2009b).

\section{Infection experiment 1}

We used 30 Ryukin and 20 Edonishiki individuals. Ryukin were divided into 3 groups of 10 fish each. Fish of one group were intraperitoneally (IP) injected with $0.1 \mathrm{ml}$ of supernatant of virus-infected cell culture of the GFF cell line with a titre of $10^{2.1} \mathrm{TCID}_{50}$ $\mathrm{ml}^{-1}$ (titrated in the GFF cell line). The second group was injected with cell culture medium without virus as the negative control. Fish of the third group were immersed for $1 \mathrm{~h}$ in the supernatant of virus culture $\left(10^{2.1} \mathrm{TCID}_{50} \mathrm{ml}^{-1}\right)$ diluted at 1:1000 with well water. Edonishiki were divided into 2 groups of 10 fish each. One group was IP injected with $0.1 \mathrm{ml}$ of the viral culture supernatant $\left(10^{2.1} \mathrm{TCID}_{50} \mathrm{ml}^{-1}\right)$. The other group was injected with cell culture medium as the negative control. All experimental groups were kept in $60 \mathrm{l}$ tanks at $20.7^{\circ} \mathrm{C}$ and fed a commercial diet (SakiHikari ${ }^{\circledR}$, Kyorin) once a day and were observed over a 4 wk period. The caudal fin, gill, brain and kidney of all dead fish and surviving fish were tested for CyHV-2 by PCR (Waltzek et al. 2009b) as described above. The kidneys of Ryukin that died from IP injection with the virus were used for virus re-isolation. The experimental design and fish size of each group in the experiment are summarized in Table 1.

\section{Infection experiment 2}

Sixty Edonishiki individuals were divided into 3 groups of 20 fish each. Fish of 2 groups were immersed for $1 \mathrm{~h}$ in the viral culture supernatant $\left(10^{2.1} \mathrm{TCID}_{50} \mathrm{ml}^{-1}\right)$ diluted at 1:1000 with well water. The third group was immersed similarly in diluted cell culture medium without the virus as a negative control. Experimental groups were kept in $60 \mathrm{l}$ tanks at $25.0^{\circ} \mathrm{C}$ and fed commercial diet (Saki-Hikari ${ }^{\circledR}$, Kyorin) once a day. Fish of one infected group and the negative control group were observed for cumulative mortality for $31 \mathrm{~d}$. To investigate the prevalence of the CyHV-2 among the organs after infection, the second group of infected fish was sampled on selected days (Days 1, 4, 8, 11, 13, 14, 15 and 17) following viral exposure by immersion, and the caudal fin, gill, heart, intestine, spleen, brain and kidney of 3 of the surviving fish and all dead individuals were tested for CyHV-2 by PCR. The kidneys of all infected fish of the group for mortality observations were used for virus re-isolation. The experimental design and fish size of each group in the experiment are summarized in Table 1.

\section{Virus re-isolation from experimental fish}

In Expt 1, homogenate of kidney from the dead fish was prepared using approximately 50 times volume of MEM and filtered $(0.45 \mu \mathrm{m})$. Then $500 \mu \mathrm{l}$ of the inoculum were added to a $25 \mathrm{~cm}^{2}$ flask containing a freshly prepared suspension of GFF cells (approximately $1 \times 10^{5}$ cells ml $^{-1}$ ) in $10 \mathrm{ml}$ of MEM. In Expt 2 , 
Table 1. Carassius auratus. Experimental design, and mean $\pm \mathrm{SD}$ of total length and body weight of fish used in this study

\begin{tabular}{|c|c|c|c|c|c|}
\hline Experiment & Variety & Treatment & $\mathrm{n}$ & Total length $(\mathrm{cm})$ & Body weight (g) \\
\hline \multirow[t]{5}{*}{1} & Ryukin & Intraperitoneal injection & 10 & $7.41 \pm 0.66$ & $11.2 \pm 1.98$ \\
\hline & & Immersion & 10 & $7.35 \pm 0.51$ & $10.1 \pm 2.10$ \\
\hline & & Negative control & 10 & $7.50 \pm 0.56$ & $11.8 \pm 2.00$ \\
\hline & Edonishiki & Intraperitoneal injection & 10 & $6.03 \pm 0.76$ & $8.64 \pm 2.38$ \\
\hline & & Negative control & 10 & $5.56 \pm 0.48$ & $7.34 \pm 1.42$ \\
\hline \multirow[t]{4}{*}{2} & Edonishiki & Immersion & & & \\
\hline & & Group for mortality observation & 20 & $7.02 \pm 0.62$ & $14.4 \pm 2.85$ \\
\hline & & Group for sampling & 20 & $6.82 \pm 0.55$ & $13.5 \pm 3.03$ \\
\hline & & Negative control & 20 & $6.56 \pm 0.42$ & $13.1 \pm 2.60$ \\
\hline
\end{tabular}

the homogenate of the kidney was prepared in the same manner as in Expt 1. Culture medium of GFF cell monolayer that was $1 \mathrm{~d}$ old was removed from the prepared flask, and $500 \mu$ l of the inoculum were added and absorbed at $25^{\circ} \mathrm{C}$ for $1 \mathrm{~h}$, and then fresh medium supplemented with $10 \%$ FBS was added to the flask.

\section{Statistical analysis}

The statistical difference between each infected group and negative control group was determined by Fisher's exact test. Differences at $\mathrm{p}<0.01$ were considered significant.

\section{RESULTS}

\section{Sustainable propagation of CyHV-2 using cell lines}

Sustainable propagation of CyHV-2 was successful in GFF cells and SRTF cells, whereas no CPE was observed in RKF cells. The CPE induced by CyHV-2 in GFF and SRTF cell cultures was similar and was characterized by granulation, cytoplasmic vacuolization, syncytium formation in focal areas and the appearance of rounded bright cells (Fig. 1). Holes appeared in the cell monolayer at 7 to $10 \mathrm{~d}$ post inoculation, where cells had detached from the plastic substrate.

The appearance of CPE was more rapid in SRTF than in GFF cell cultures, and the sensitivity of SRTF cells to CyHV-2 was higher than GFF cells (data not shown). However, the cost of maintaining SRTF cells is higher than GFF cells, since SRTF requires the flask to be coated with collagen, which is expensive, and the sub-culture split ratio is only 1:2. Therefore, GFF cells were used for the preparation of inocula for experimental infections in this study. In addition, propagation of the virus at 15,20 and $25^{\circ} \mathrm{C}$ was investigated in advance, and it was observed that the completion was most rapid at $25^{\circ} \mathrm{C}$. Consequently, CyHV-2 was propagated using GFF cells sustainably beyond 12 passages by the method described in 'Materials and methods'.

\section{Infection experiment 1}

Cumulative mortality curves of Expt 1 and results of CyHV-2 DNA detection by PCR and re-isolation of the virus from dead fish are shown in Fig. 2a and Table 2. The fish inoculated with the virus showed cumulative mortality of $30 \%$, after immersion infection of Ryukin, and 90 and $100 \%$ after IP injection of Edonishiki and Ryukin, respectively. The mortality rates in the IP injection group of Ryukin and Edonishiki were significantly higher compared with the respective negative controls. The mortality in the immersion group of Ryukin was not significantly different.

CyHV-2 DNA was detected in all tested organs of all dead fish in the IP-injected Ryukin. In the group of immersed Ryukin, viral DNA was detected by PCR from a surviving fish as well as a dead fish. Positive rates of detection were particularly high from gills and kidney. In the group of infected Edonishiki, viral DNA was detected from the kidney of all dead and surviving fish. There was no mortality in either of the negative controls, and viral DNA was not detected from the kidney of the negative control of either variety.

Using a freshly prepared GFF cell suspension, virus was re-isolated from only $20 \%(2 / 10)$ of dead IP-injected Ryukin. In this trial, extensive cytotoxicity effect (CTE) was observed from the 8 other samples. It is possible that the kidney homogenate might be toxic to freshly prepared suspensions of GFF cells. 

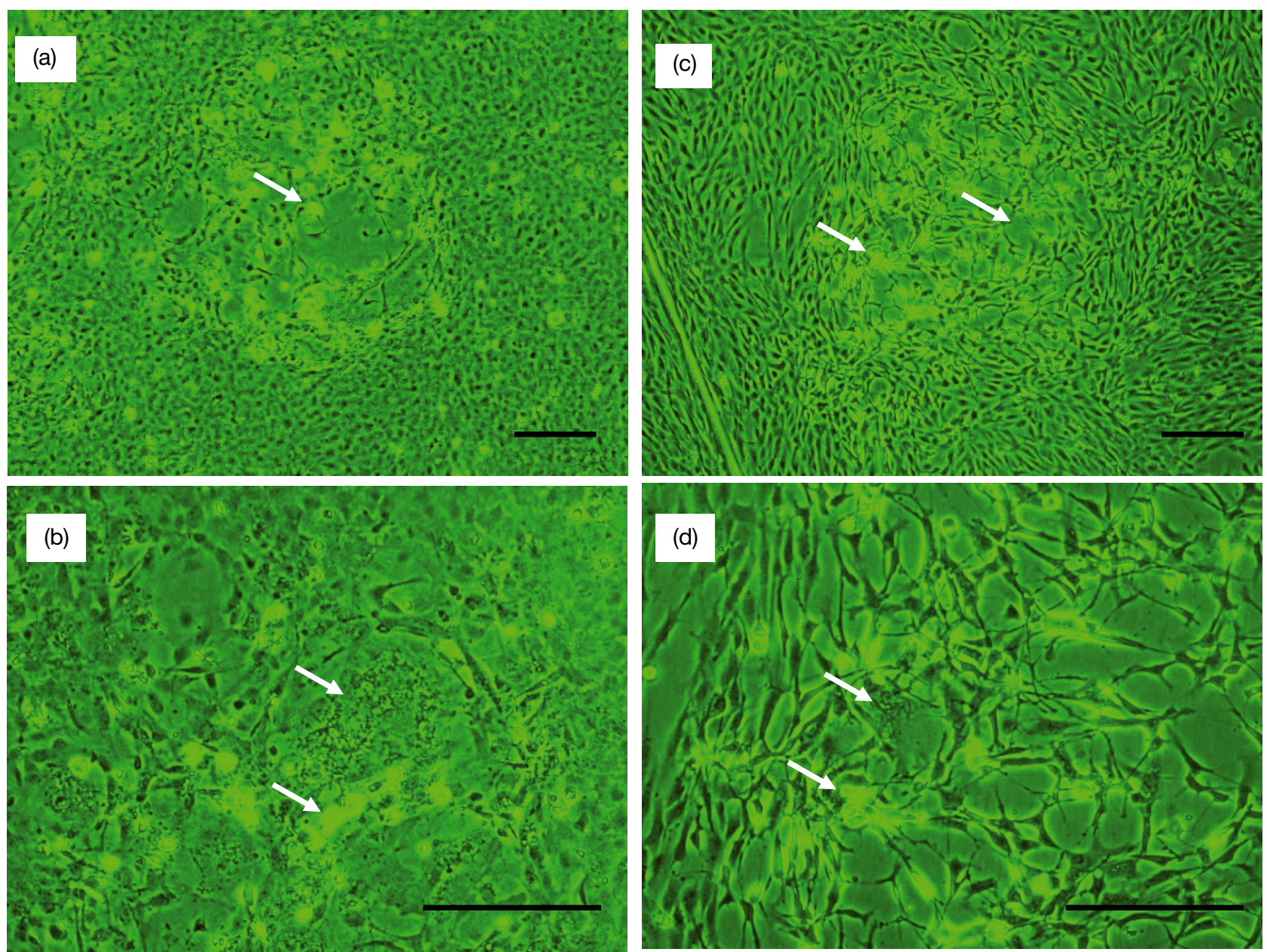

Fig. 1. Carassius auratus. Cytopathic effect (CPE) induced by CyHV-2. (a) CPE on GFF cells at $10 \mathrm{~d}$ post inoculation (dpi) at $25^{\circ} \mathrm{C}(\times 40)$. Note detachment of cells at focal areas and appearance of rounded bright cells. (b) CPE on GFF cells at 10 dpi $(\times 100)$. Note granulation, syncytium formation and appearance of rounded bright cells. (c) CPE on SRTF cells at 4 dpi at $25^{\circ} \mathrm{C}$ $(\times 40)$. Note detachment of cells at focal areas and appearance of rounded bright cells. (d) CPE on SRTF cells at $4 \mathrm{dpi}(\times 100)$. Note syncytium formation and appearance of rounded bright cells. Scale bars $=200 \mu \mathrm{m}$

\section{Infection experiment 2}

Cumulative mortality curves of Expt 2 and results of CyHV-2 DNA detection by PCR and re-isolation of virus from all fish are shown in Fig. $2 \mathrm{~b}$ and Table 2. The Edonishiki which were treated by immersion with the virus showed a cumulative mortality of $90 \%$. The mortality rate was significantly higher compared with the negative control. The affected fish showed a normal appetite after exposure to the virus for approximately $1 \mathrm{wk}$ and swam actively. However, a few days before their death, the fish suddenly became lethargic and stayed at the bottom of the tank or at the surface of the water. Extreme pallor of the gills was observed in the infected dead fish (Fig. 3).

Viral DNA was detected by PCR from the kidney of all dead and surviving fish. There was no mortality in the negative control group, and viral DNA was not detected from any negative control fish. The virus was re-isolated from the kidneys of 17 of 18 dead fish. No CPE was observed in cultures inoculated with samples from surviving fish.

\section{Sequential detection of CyHV-2 DNA from fish in Expt 2}

The sequential detection of CyHV-2 DNA by PCR from the caudal fin, gill, heart, intestine, spleen, brain and kidney of infected Edonishiki sampled at certain intervals is shown in Table 3. Photographs of some representative agarose gels after electrophoresis are shown in Appendix 1. CyHV-2 DNA was not detected from all the tested organs of 3 sacrificed fish 


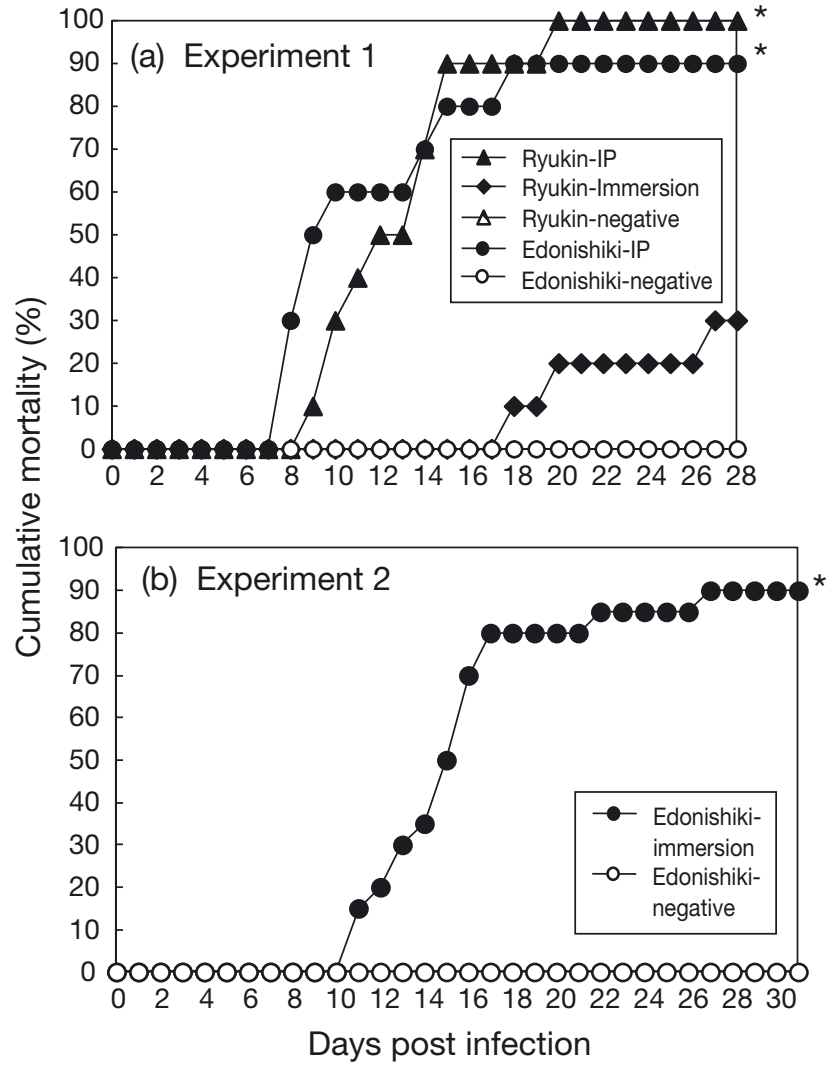

Fig. 2. Carassius auratus. Cumulative mortality curves for goldfish experimentally infected with CyHV-2. (a) Infection experiment 1: $(\boldsymbol{\Delta})$ : Ryukin intraperitoneally injected with CyHV-2; $(\diamond)$ : Ryukin infected by immersion of CyHV-2; $\left(\Delta_{i}\right.$ hidden behind open circles): negative control Ryukin; $(\mathbf{O})$ : Edonishiki intraperitoneally injected with CyHV-2; (O): negative control Ryukin. (b) Infection experiment 2: (O): Edonishiki infected by immersion of CyHV-2; (O): negative control Edonishiki. Asterisks indicate that the mortality rate at the end of the experiment was significantly different from the negative control ( $p<0.01$ by Fisher's exact test)

at 1 and 4 d post exposure (dpe), and viral DNA was detected from 2 of the 3 fish from the caudal fin, and heart, intestine and spleen on 8 dpe from sub-clinical fish (Appendix 1). At 10 dpe, 1 fish was lethargic and stayed at the surface of the water, and then died at 11 dpe. Viral DNA was detected from all tested organs of the dead fish. The amplicons resolved by electrophoresis were bright and dense, as was the sample of DNA extracted from CyHV-2 as a positive control. At 13 dpe, 4 fish died and viral DNA was detected from all the tested organs of the dead fish. Although viral DNA was also detected from all tested organs in 2 of 3 surviving fish at 14 dpe, it was not detected from the intestine of 1 of these 3 fish. Moreover, the amplicons from the gill, heart, spleen and brain of the surviving fish were less bright and dense

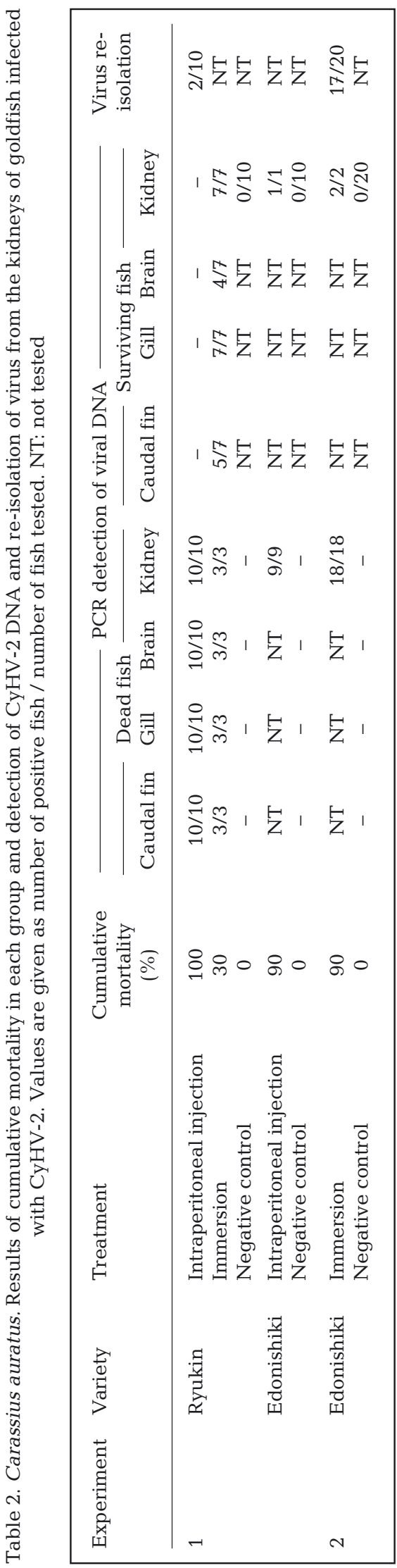




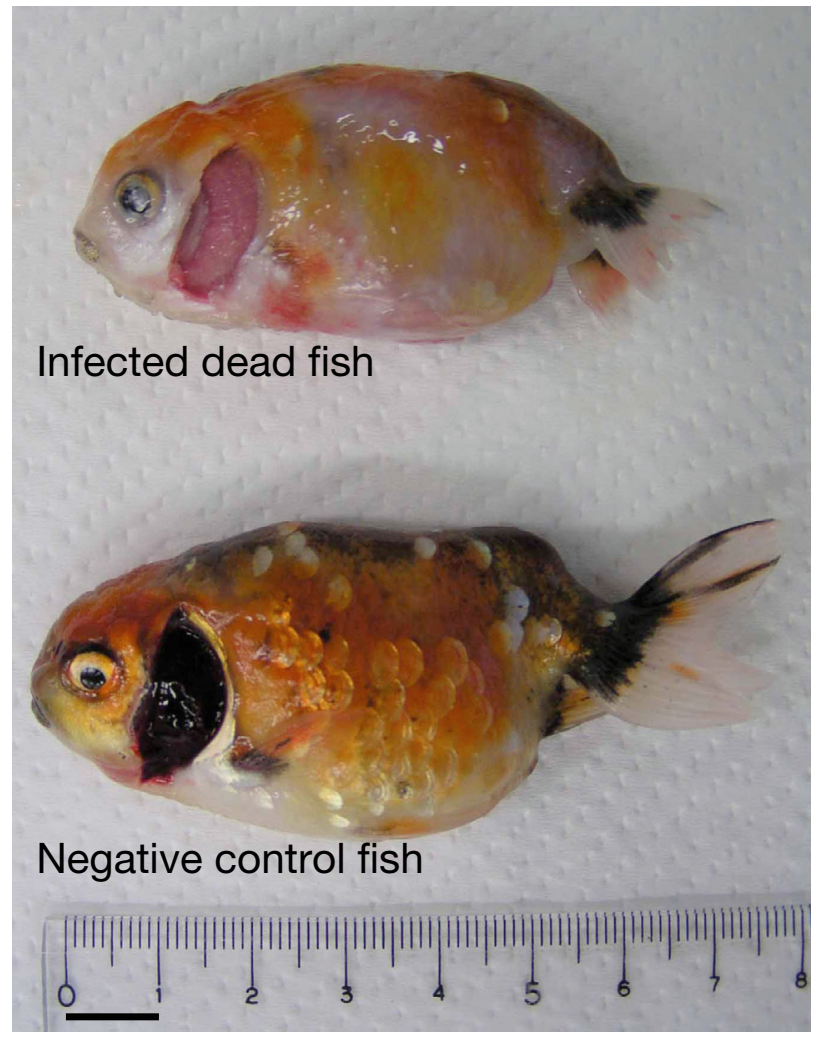

Fig. 3. Carassius auratus. Dead fish (Edonishiki) in infection experiment 2 at $14 \mathrm{~d}$ after exposure by immersion of CyHV2. The dead fish demonstrated extremely pale gills compared to the negative control fish. Bar $=1 \mathrm{~cm}$

than those of the other samples (Appendix 1). Viral DNA was detected from all tested organs of 2 dead fish at 15 dpe and 1 dead fish at 17 dpe. At 31 dpe, which was the final day of the infection trial, the organs of the 2 surviving fish from the group of observation on mortality were investigated. CyHV-2 DNA was detected from the heart, intestine and kidney of 1 of the 2 fish, and was detected from the gill, spleen and kidney of the other fish. However, these amplicons were less bright and dense than those of other samples of dead fish (Appendix 1).

\section{DISCUSSION}

This paper is the first report to detail methods for continuous propagation of CyHV-2 using cell lines as well as results of successful experimental infection of goldfish by intraperitoneal injection and immersion with the propagated virus in vitro.

In this study, we could demonstrate that CyHV-2 was continuously propagated using cultures of GFF and the newly established SRTF cell lines using the described inoculation and passage techniques. In the first report of HVHN caused by CyHV-2 (Jung \& Miyazaki 1995), while initial viral isolation and propagation were achieved using epithelioma papulosum cyprini and FHM cell cultures, CyHV-2 could not be sub-cultured beyond the fourth passage in vitro. The same phenomenon has been reported in other studies using KF-1 cells (Jeffery et al. 2007, Wang et al. 2012). Although Li \& Fukuda (2003) mentioned successful propagation of CyHV-2 using GFF cells, methods for propagation of the virus were not detailed. We adopted 2 viral culture techniques: (1) the normal inoculation of harvested virus culture supernatant to a freshly prepared GFF cell suspension, and (2) where CPE progression is slow, sub-culture of the infected GFF cell monolayer. This inoculation and sub-culture method can be used to reliably propagate virus continuously in GFF cells for 12 sub-cultures. Furthermore, we have shown that virus which had been subcultured 7 times in GFF cell cultures retained virulence when used to infect goldfish by immersion challenge. Indeed, we succeeded in obtaining a CyHV-2 isolate from a diseased goldfish and sub-cultured it several times using the same techniques (data not shown). We observed high mortality rates in experimental infection trials of 2 varieties of goldfish, Ryukin and Edonishiki, infected with the GFF cell grown virus.

While there is the possibility that susceptibility to infection with CyHV-2 varies between goldfish varieties, the cumulative mortality rates in Ryukin and Edonishiki experimentally infected by IP inoculation in this study were very similar. It would be interesting to extend this study to compare susceptibility to infection by immersion challenge. Nevertheless, results from this study indicate that there is no difference in susceptibility to infection/disease between these 2 varieties.

Expts 1 and 2 were performed at 20 and $25^{\circ} \mathrm{C}$, respectively. Although we cannot directly compare the results of the experiments, the progression of the disease appeared to be more rapid at 25 than at $20^{\circ} \mathrm{C}$.

When the inoculum of the homogenate of kidney for re-isolation was added to the GFF cell suspension, 8 of 10 samples in Expt 1 showed extensive CTE. However, in Expt 2, virus re-isolation from dead fish at a high rate was achieved using the method by which the inoculum was absorbed onto GFF cells for $1 \mathrm{~h}$ (Table 2). Thus the latter method is currently recommended for virus isolation using GFF cell cultures. A remaining sample from which virus could not be re-isolated was obtained from a dead fish at 27 dpe, suggesting that the viral titre in the kidney was too low for re-isolation. 
Table 3. Carassius auratus. Detection of viral DNA from the organs of goldfish exposed to CyHV-2 (infection experiment 2). -: negative; +: positive (number of + shows the brightness and density of the bands after electrophoresis)

\begin{tabular}{|c|c|c|c|c|c|c|c|c|c|}
\hline \multirow{2}{*}{$\begin{array}{l}\text { Days post } \\
\text { exposure }\end{array}$} & \multirow{2}{*}{$\begin{array}{c}\text { Sample } \\
\text { no. }\end{array}$} & \multirow{2}{*}{$\begin{array}{l}\text { Disease } \\
\text { stage }\end{array}$} & \multicolumn{7}{|c|}{ - Organ } \\
\hline & & & Caudal fin & Gill & Heart & Intestine & Spleen & Brain & Kidney \\
\hline \multirow[t]{3}{*}{1} & 1 & Sub-clinical & - & - & - & - & - & - & - \\
\hline & 2 & Sub-clinical & - & - & - & - & - & - & - \\
\hline & 3 & Sub-clinical & - & - & - & - & - & - & - \\
\hline \multirow[t]{3}{*}{4} & 1 & Sub-clinical & - & - & - & - & - & - & - \\
\hline & 2 & Sub-clinical & - & - & - & - & - & - & - \\
\hline & 3 & Sub-clinical & - & - & - & - & - & - & - \\
\hline \multirow[t]{3}{*}{8} & 1 & Sub-clinical & + & - & - & - & - & - & - \\
\hline & 2 & Sub-clinical & - & - & ++ & ++ & + & - & - \\
\hline & 3 & Sub-clinical & - & - & - & - & - & - & - \\
\hline 11 & 1 & Dead & +++ & +++ & +++ & +++ & +++ & +++ & +++ \\
\hline \multirow[t]{4}{*}{13} & 1 & Dead & +++ & +++ & +++ & +++ & +++ & +++ & +++ \\
\hline & 2 & Dead & +++ & +++ & +++ & +++ & +++ & +++ & +++ \\
\hline & 3 & Dead & +++ & +++ & +++ & +++ & +++ & +++ & +++ \\
\hline & 4 & Dead & +++ & +++ & +++ & +++ & +++ & +++ & +++ \\
\hline \multirow[t]{3}{*}{14} & 1 & Surviving & +++ & +++ & +++ & +++ & +++ & +++ & +++ \\
\hline & 2 & Surviving & +++ & +++ & +++ & +++ & +++ & +++ & +++ \\
\hline & 3 & Surviving & +++ & + & + & - & + & + & +++ \\
\hline \multirow[t]{2}{*}{15} & 1 & Dead & +++ & +++ & +++ & +++ & +++ & +++ & +++ \\
\hline & 2 & Dead & +++ & +++ & +++ & +++ & +++ & +++ & +++ \\
\hline 17 & 1 & Dead & +++ & +++ & +++ & +++ & +++ & +++ & +++ \\
\hline \multirow[t]{2}{*}{31} & 1 & Surviving $^{\mathrm{a}}$ & - & - & + & + & - & - & + \\
\hline & 2 & Surviving $^{\mathrm{a}}$ & - & ++ & - & - & ++ & - & ++ \\
\hline
\end{tabular}

In the study designed for detection of viral DNA in sequential tissue samples taken from CyHV-2 infected fish, viral DNA was first detected in several organs from 2 of the 3 fish sampled at 8 dpe. By 11 dpe, viral DNA was detected in all tissue samples from all dead fish. It is interesting to note that Jeffery et al. (2007) reported that moribund fish became lethargic, gathered at the surface and died within $24 \mathrm{~h}$ after the water temperature increased from $14-15^{\circ} \mathrm{C}$ to the permissive temperature of $19-21^{\circ} \mathrm{C}$. Taken together with the results of this study, it appears that CyHV-2 titres increase in infected fish to detectable levels, followed by the appearance of clinical signs, which, in turn, is followed rapidly by death.

In contrast, for CyHV-3, which belongs to the same genus Cyprinivirus of the Alloherpesviridae, Gilad et al. (2004) reported that the CyHV-3 DNA was detected by real-time TaqMan PCR from most of the tested organs of infected carp after 1 dpe, and Yuasa et al. (2012) reported that the virus was isolated from the gills of carp from 3 dpe. Compared with the results of our study, it appears that the viral kinetics of CyHV-2 in goldfish differ greatly from those of CyHV-3 in carp.
In both experimental infections in this study, viral DNA was detected from all of the tested organs of all dead fish and was detected from the kidney of all surviving fish at $28 \mathrm{~d}$ post infection and $31 \mathrm{dpe}$ (Table 2). These results show that systemic infection occurs in goldfish and also that the kidney is a main multiplication site. Goodwin et al. (2006b) reported that the highest copy number of viral DNA was consistently detected by quantitative PCR from the spleen and kidney of naturally diseased goldfish showing gross signs of CyHV-2 infection. Therefore, we suggest that the kidney is the most suitable organ for viral DNA detection by PCR.

Naturally diseased fish resulting from CyHV-2 infection do not usually show any specific external signs (Jung \& Miyazaki 1995). Results from experimental infection trials in our study support these observations. Although small white patches on the external body surface were observed on a few dead fish, the signs which were reported by Stephens et al. (2004) and by Jeffery et al. (2007) were not typical in our study. Internally, most of the dead fish in our study displayed an enlarged spleen, which is consistent with other reports (Jung \& Miyazaki 1995, Groff et al. 1998, Stephens et al. 2004, Jeffery et al. 2007). 
While there was a lack of pathognomonic clinical signs due to CyHV-2 infection in this study, we did observe in the immersion infection experiment (Expt 2) a behavioural change (lethargy) which occurred just a few days before death. This characteristic of CyHV-2 infection may be the reason that goldfish farmers have difficulty in detecting infected fish on-farm. In fact, it is likely that farmers may harvest infected, but healthy looking, fish for transport to market (wholesaler), since CyHV-2-infected fish look healthy for several days after initial infection. Of particular interest, in Japan most harvested goldfish are kept for a few days in the same pond at auctions, thus providing ideal conditions for disease transmission. Consequently, CyHV-2 infection of goldfish is a problem not only on-farm but also for fish held in markets, at retail sites and by private owners.

Acknowledgements. This study was funded by the Fisheries Research Agency in Japan. We are grateful for the technical support and useful advice from colleagues of the National Research Institute of Aquaculture, Fisheries Research Agency in Japan.

\section{LITERATURE CITED}

Aichi Prefecture (2008) Introduction to work conducted at the General Affairs Division, Department of Agriculture, Forestry, and Fisheries, Aichi Prefectural Government. Available at www.pref.aichi.jp/0000009518.html (in Japanese) (accessed 6 May 2013)

Chang PH, Lee SH, Chiang HC, Jong MH (1999) Epizootic of herpes-like virus infection in goldfish, Carassius auratus in Taiwan. Fish Pathol 34:209-210

Daněk T, Kalous L, Veselý T, Krásová E and others (2012) Massive mortality of Prussian carp Carassius gibelio in the upper Elbe basin associated with herpesviral hematopoietic necrosis (CyHV-2). Dis Aquat Org 102:87-95

Gilad O, Yun S, Zagmutt-Vergara FJ, Leutenegger CM, Bercovier H, Hedrick RP (2004) Concentrations of a koi herpesvirus (KHV) in tissues of experimentally-infected Cyprinus carpio koi as assessed by real-time TaqMan PCR. Dis Aquat Org 60:179-187
Goodwin AE, Khoo L, LaPatra SE, Bonar C and others (2006a) Goldfish hematopoietic necrosis herpesvirus (Cyprinid herpesvirus 2) in the USA: molecular confirmation of isolates from diseased fish. J Aquat Anim Health 18:11-18

Goodwin AE, Merry GE, Sadler J (2006b) Detection of the herpesviral hematopoietic necrosis disease agent (Cyprinid herpesvirus 2) in moribund and healthy goldfish: validation of a quantitative PCR diagnostic method. Dis Aquat Org 69:137-143

Groff JM, LaPatra SE, Munn RJ, Zinkl JG (1998) A viral epizootic in cultured populations of juvenile goldfish due to a putative herpesvirus etiology. J Vet Diagn Invest 10: 375-378

Hine PM, Tham KM, Morrison R (2006) Cyprinid herpesvirus 2 in New Zealand goldfish. Surveillance 33:3-5

- Jeffery KR, Bateman K, Bayley A, Feist SW and others (2007) Isolation of a cyprinid herpesvirus 2 from goldfish, Carassius auratus (L.), in the UK. J Fish Dis 30: 649-656

Jung SJ, Miyazaki T (1995) Herpesviral haematopoietic necrosis of goldfish, Carassius auratus (L.). J Fish Dis 18: 211-220

Li X, Fukuda H (2003) In vitro culture of goldfish cell sensitive to goldfish herpesvirus. J Shanghai Fish Univ 12: $12-18$

> Stephens FJ, Raidal SR, Jones B (2004) Haematopoietic necrosis in a goldfish (Carassius auratus) associated with an agent morphologically similar to herpesvirus. Aust Vet J 82:167-169

Waltzek TB, Kelley GO, Stone DM, Way K and others (2005) Koi herpesvirus represents a third cyprinid herpesvirus (CyHV-3) in the family Herpesviridae. J Gen Virol 86: 1659-1667

> Waltzek TB, Kelley GO, Alfaro ME, Kurobe T, Davison AJ, Hedrick RP (2009a) Phylogenetic relationships in the family Alloherpesviridae. Dis Aquat Org 84:179-194

$>$ Waltzek TB, Kurobe T, Goodwin AE, Hedrick RP (2009b) Development of a polymerase chain reaction assay to detect cyprinid herpesvirus 2 in goldfish. J Aquat Anim Health 21:60-67

Wang L, He J, Liang L, Zheng X and others (2012) Mass mortality caused by cyprinid herpesvirus 2 (CyHV-2) in Prussian carp (Carassius gibelio) in China. Bull Eur Assoc Fish Pathol 32:164-173

- Yuasa K, Sano M, Oseko N (2012) Effective procedures for culture isolation of koi herpesvirus (KHV). Fish Pathol 47: 97-99 
(a) Sub-clinical individuals at 4 days post exposure (dpe)

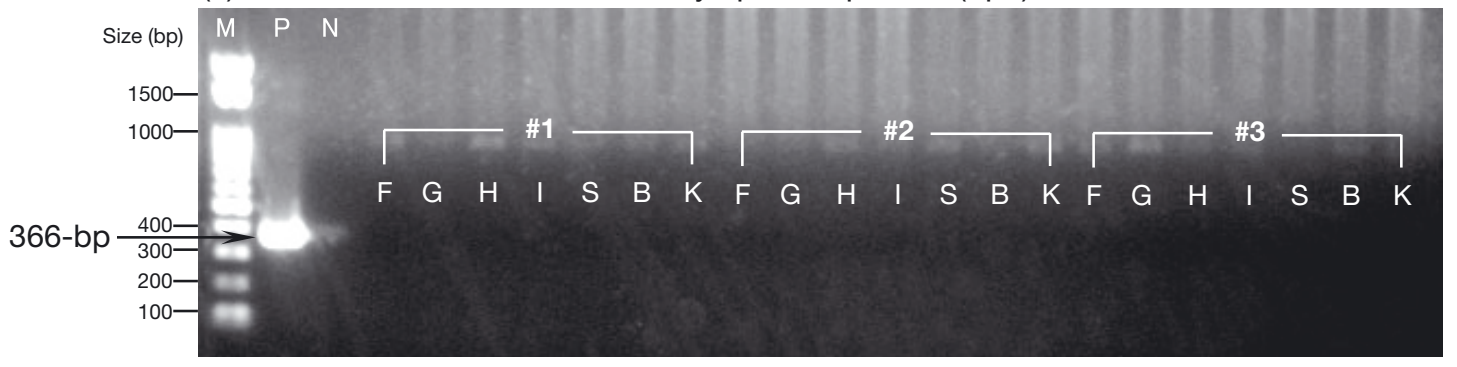

(b) Sub-clinical individuals at 8 dpe

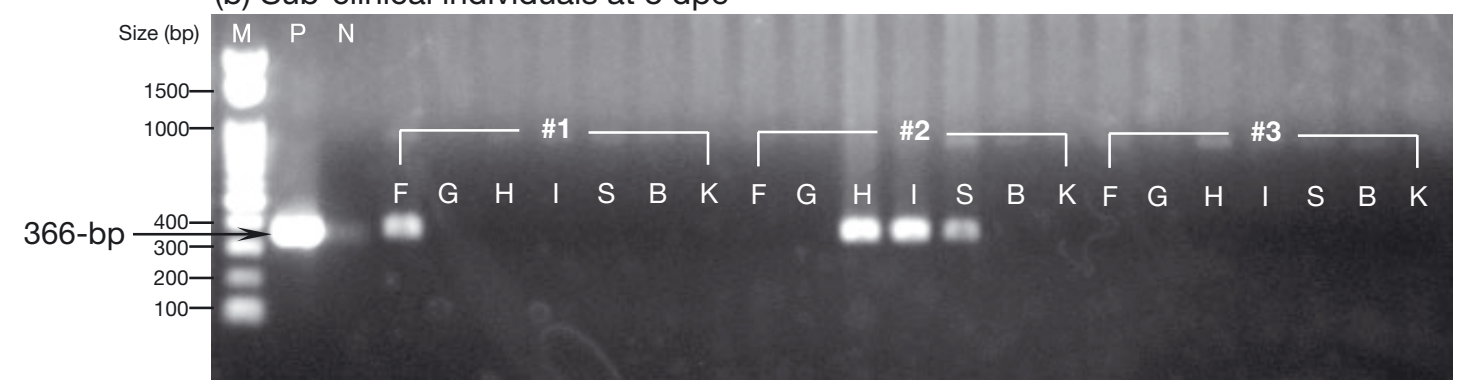

(c) Dead individuals at 13 dpe

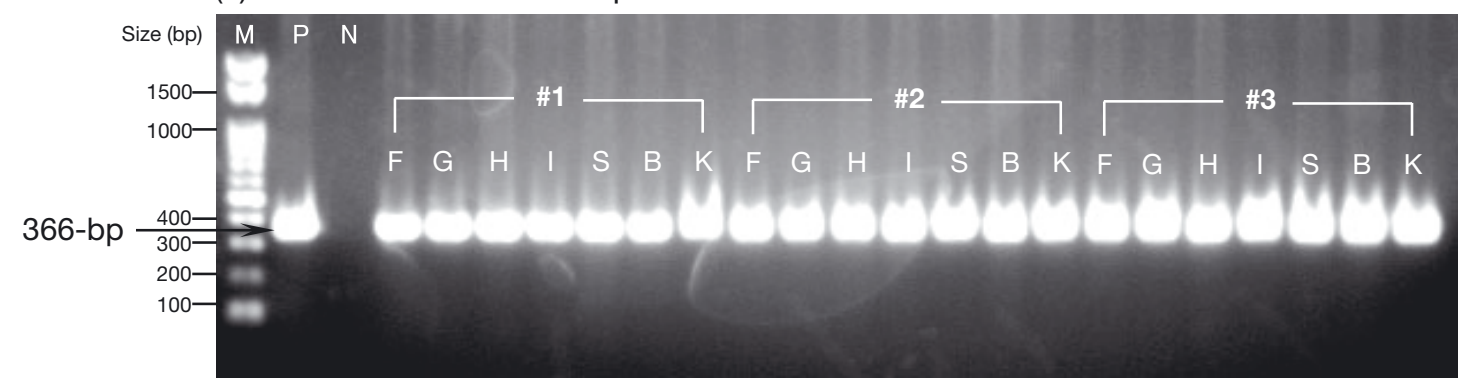

(d) Surviving individuals at 14 dpe

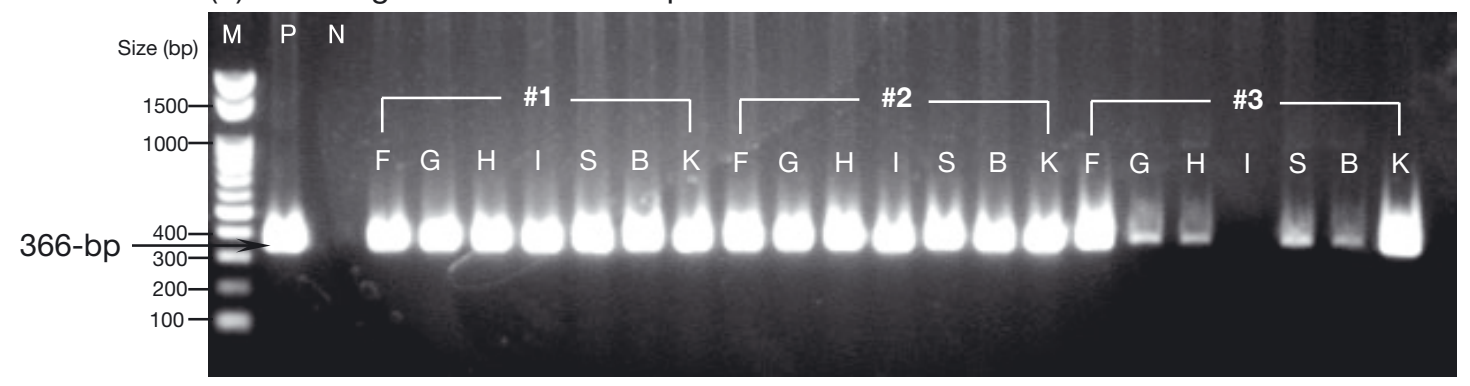

(e) Surviving individuals at 31 dpe

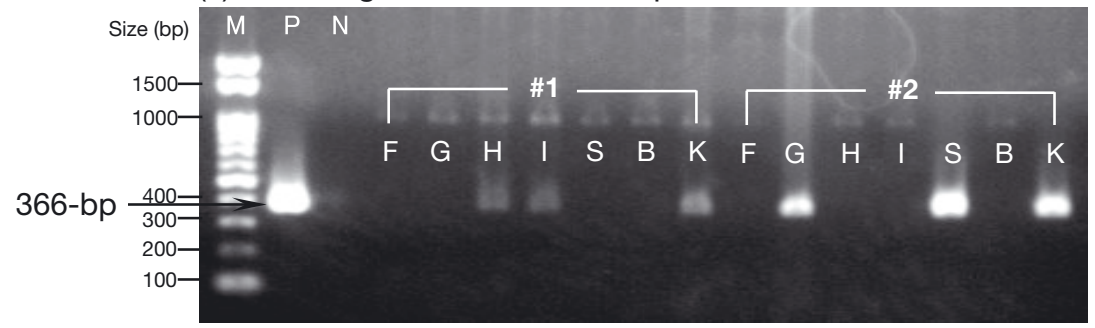

Appendix 1. Detection of CyHV-2 DNA from the organs of goldfish exposed to CyHV-2 by PCR using specific primers targetting the helicase gene of CyHV-2 (Waltzek et al. 2009). Arrow indicates position of the 366-bp amplicon. M, Molecular weight markers (Wako, Gene Ladder 100); P, positive control; $\mathrm{N}$, negative control; $\mathrm{F}$,

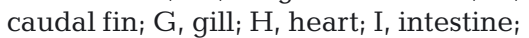
$\mathrm{S}$, spleen; $\mathrm{B}$, brain; $\mathrm{K}$, kidney 